\title{
FURTHER EXPERIENCES WITH FENTANYL AND DROPERIDOL
}

\author{
G. DRUMMOND, F.R.C.P.(C), AND J. W. R. MCINTYRE, F.F.A.R.C.S."
}

INITIAL EXPERIENCE with fentanyl and dihydrobenzperidol containing 25 per cent of an analogue benzperidol indicated that a combination of these drugs could be of value during induction or maintenance of general anaesthesia. ${ }^{1}$ of particular interest was the frequency with which patients recovered consciousness while remaining in an analgesic state which persisted for some time, thus permitting full assessment of their condition before additional drugs were required.

Dihydrobenzperidol without the analogue already mentioned, and fentanyl, have subsequently been made available in a combination also referred to as Innovar (McNeil). Each millilitre of this solution contains $0.05 \mathrm{mg}$. of fentanyl and $2.5 \mathrm{mg}$. dihydrobenzperidol. It is the purpose of this paper to present information regarding the use of this drug combination.

One hundred adult patients undergoing a variety of operations, including 44 major abdominal procedures 105 to 360 minutes in duration, and 21 other major procedures 90 to 310 minutes in duration, the remaining cases taking approximately an hour each, were premedicated with meperidine or morphine, atropine or hyoscine; the anaesthetic technique involved the use of thiopentone 200 to $400 \mathrm{mg}$. for induction, and maintenance with nitrous oxide $3.5 \mathrm{~L}$. $/ \mathrm{min}$. and oxygen $1.5 \mathrm{~L} . / \mathrm{min}$., delivered into a semi-closed circle absorber system. Relaxants were employed when necessary, and artificial ventilation was 50 to 100 per cent in excess of the Radford Nomogram value for the particular patient. The combination of dihydrobenzperidol and fentanyl was administered intravenously by intermittent injection at intervals of 10 to 40 minutes, the criteria for injection being the customary signs of inadequate anaesthesia, or the length of time since the previous injection. The dosage used was later calculated for each patient on a time-bodyweight basis, and appears in Figure 1 represented as millilitres administered every thirty minutes to a $70 \mathrm{~kg}$. patient. The cases have been separated into two groups because of the influence of the loading doses on the quantity used, though this is only one of the many reasons that could account for variation in drug dosage.

The routine nursing records made in the recovery room were the basis of the evaluation of the postoperative period, which was carried out by the nursing staff. Taken into consideration in this evaluation were: (1) The length of time before the patient was clearly aware of his environment and identity. (2) The analgesic or sedative drug requirements while the patient was in the recovery room. (3) Resuscitative drug requirements-though in fact none were required in this series of cases.

Indication for administration of analgesic or sedative drugs was the behaviour of the patient. If no such drugs were given in the recovery room, then the time

-Department of Anaesthesia, University of Alberta Hospital, Edmonton, Alberta. 

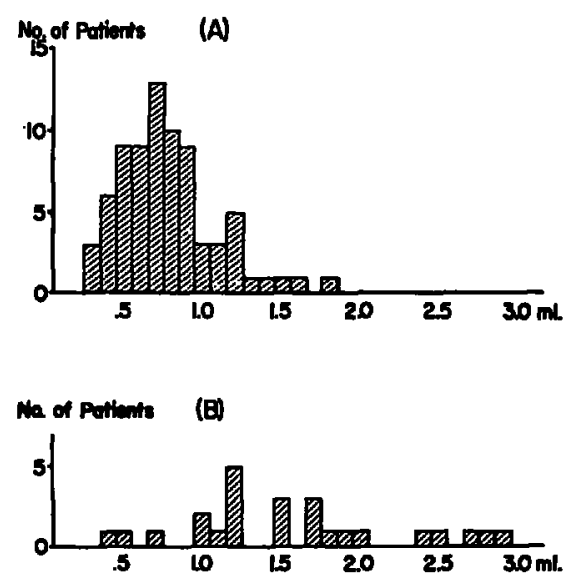

Frgune 1. Innovar dosage expressed as millilitres every 30 minutes for a $70 \mathrm{~kg}$. patient. A. Duration of surgery 90 minutes or more. B. Duration of surgery less than 90 minutes.

at which they were given on the ward was obtained the following day. The recovery time in minutes appears in Figure 2. The fact that analgesia was common at this time and subsequently is demonstrated in Figure 3, which shows

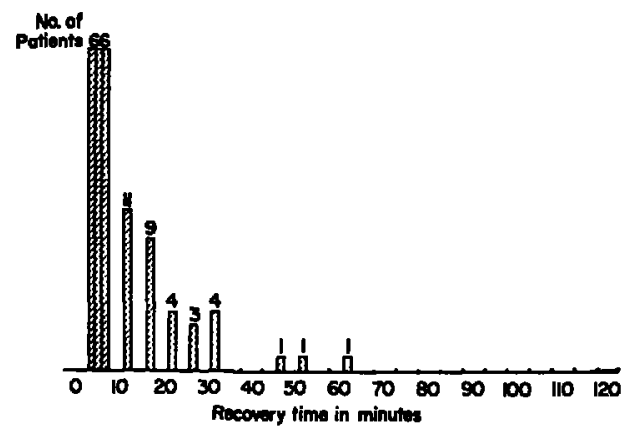

FicURe 2

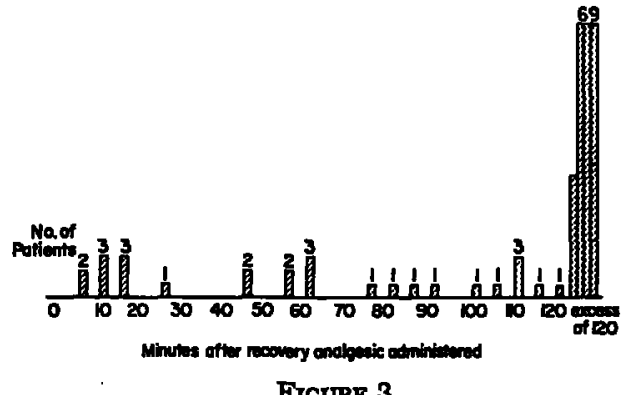

FreuRe 3

the time in minutes between recovery of consciousness and the need for analgesics. It can be seen that in a large proportion of cases there was a long period of time during which patients were aware of identity and location, but did not state that they were in pain or appear to be in any anxiety or distress.

In an attempt to compare these results with those which might be obtained using as the anaesthetic technique nitrous oxide $1 \mathrm{~L} . / \mathrm{min}$., oxygen $1 \mathrm{~L} . / \mathrm{min}$. and halothane 0.5 to 2 per cent into a semi-closed circle absorber system, each of the nitrous-oxide-droperidol-fentanyl patients was paired with one of the same sex who had received the same premedication and been anaesthetized with halothane. The similarity was extended as closely as possible to age, weight, and type and duration of surgery. The variation in time taken for awakening, and the elapsed time after awakening before analgesics were required are shown in Tables I 
and II. All the surgery terminated between 9.00 A.M. and 2.00 P.M., mostly toward the end of this period. Consequently, in considering the time of administration of analgesics it should be borne in mind that approximately 400 minutes

TABLE I

\begin{tabular}{ccc}
\hline \hline \multirow{2}{*}{$\begin{array}{c}\text { Time before awakening } \\
\text { (min.) }\end{array}$} & \multicolumn{2}{c}{ Number of patients } \\
\cline { 2 - 3 } & halothane & droperidol-fentanyl \\
\hline $0=99$ & 4 & 67 \\
$10=19$ & 21 & 19 \\
$20=29$ & 29 & 7 \\
$30=39$ & 19 & 4 \\
$40=49$ & 13 & 1 \\
$50=59$ & 5 & 1 \\
$60=69$ & 4 & - \\
$70=79$ & 1 & - \\
$80=89$ & 2 & - \\
$100=109$ & 79 & - \\
$110=119$ & 1 & 100 \\
120 and more & 1 & \\
& 100 & \\
\hline
\end{tabular}

TABLE II

\begin{tabular}{|c|c|c|}
\hline & \multicolumn{2}{|c|}{ Number of patients } \\
\hline & halothane & droperidol-fentanyl \\
\hline $\begin{array}{l}\text { Analgesics required prior } \\
\text { to consciousness } \\
\text { Time after consciousness } \\
\text { before analgesics required } \\
(\mathrm{min})\end{array}$ & 10 & 0 \\
\hline 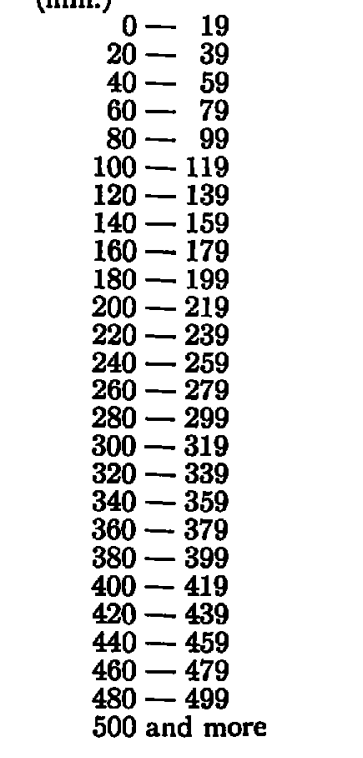 & $\begin{array}{r}20 \\
12 \\
7 \\
3 \\
3 \\
7 \\
3 \\
4 \\
1 \\
1 \\
3 \\
4 \\
0 \\
2 \\
2 \\
1 \\
3 \\
0 \\
0 \\
0 \\
0 \\
1 \\
1 \\
1 \\
0 \\
1 \\
3\end{array}$ & $\begin{array}{l}8 \\
1 \\
4 \\
4 \\
3 \\
6 \\
3 \\
5 \\
4 \\
8 \\
7 \\
8 \\
5 \\
2 \\
1 \\
2 \\
1 \\
0 \\
2 \\
2 \\
5 \\
4 \\
2 \\
1 \\
3 \\
4\end{array}$ \\
\hline & 92 & 95 \\
\hline
\end{tabular}


after consciousness the normal day-night sleep rhythms, hospital environment, and nursing habits need to be taken into consideration. The difference between the two techniques seemed to be more marked in abdominal surgery than in orthopaedics, and this may be accounted for in part by a more extensive use of artificial ventilation, or a possible potentiating action of neostigmine, or the action of fentanyl. ${ }^{2}$

The concept of parenterally administered drugs being part of a general anaesthetic technique and ensuring certain desirable features in the recovery period is an attractive one, exemplified by the effects of intramuscular morphine premedication prior to a short surgical procedure. However, the choice of nitrous oxide, fentanyl, and droperidol as complementary agents does not seem ideal. In patients whose drug requirements seem high the respiratory depressant effect of fentanyl is a restraining influence on the quantity used and is difficult to monitor in the artificially ventilated patient, while properidol may not provide the necessary pharmacological requirements. Nitrous oxide as the only available alternative for depression of the nervous system may occasionally conflict with the oxygen requirements of the patient. If marked hyperventilation is employed this may on occasion be a physiological embarrassment. Additional factors to be taken into consideration in the use of nitrous oxide are diffusion hypoxia, the possibility of denitrogenation, hypoxia, and availability of the drug. Thus, it seemed reasonable to study other pharmacological possibilities. Intermittent Innovar during anaesthesia with halothane, or methoxyflurane vaporized with oxygen, was used initially, but the analgesic qualities of methoxyflurane in low concentration made it the more suitable agent for this purpose.

Sixty patients scheduled for abdominal or orthopaedic procedures were premedicated with atropine alone, and anaesthesia was induced with thiopentone 200 to $400 \mathrm{mg}$, and $4 \mathrm{~L}$. $/ \mathrm{min}$. of oxygen containing approximately 0.5 to 1.0 per cent methoxyflurane into a semi-closed circle absorber system for 15 minutes. Maintenance was with $4 \mathrm{~L}$. $/ \mathrm{min}$. of methoxyflurane approximately 0.1 to 0.5 per cent, and intermittent intravenous injections of dihydrobenzperidol and fentanyl. Relaxants were used when necessary, and artificial ventilation 50 to 100 per cent in excess of the Radford Nomogram value was employed in many cases. The observations made were similar to those in the first series and are presented in the same fashion. In Figure 4 the dosage used is shown, expressed as millilitres

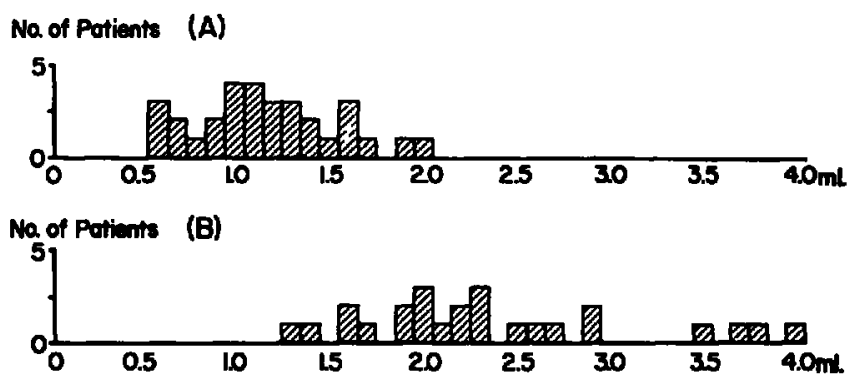

FiguRE 4. Innovar dosage expressed as millilitres every 30 minutes for a $70 \mathrm{~kg}$. patient. A. Duration of surgery 90 minutes or more. B. Duration of surgery less than 90 minutes. 
per 30 minutes for a $70 \mathrm{~kg}$. patient. Again a distinction has been drawn between operations up to 90 minutes and those lasting longer. The dosage used is more variable than was the case with nitrous oxide, almost certainly because of variation in methoxyflurane dosage.

The length of time for the criteria of consciousness to be satisfied is shown in Figure 5. It tended to be longer than following nitrous oxide, but not inconveniently so. The use of a Pentec vaporizer permitted more accurate control of methoxyflurane administration than a Boyle's bottle, and it was the Boyle vaporizer which was employed in the five patients who took particularly long to regain consciousness. The time at which analgesic drugs were required is shown in Figure 6. In all but two cases consciousness had been regained some minutes before additional drugs were needed.

In conclusion, the use of methoxyflurane, oxygen or oxygen and air, fentanyl, and droperidol is a feasible anaesthetic technique permitting the use of an analgesic and psychopharmacologic agent that can be administered by the intravenous and, after surgery, the intramuscular route. Thus a drug supplying preoperative and postoperative requirements is supplemented during surgery by an inhalational agent. The use of an analgesic in combination with a drug that is said to be associated with analgesia in the recovery period is not illogical

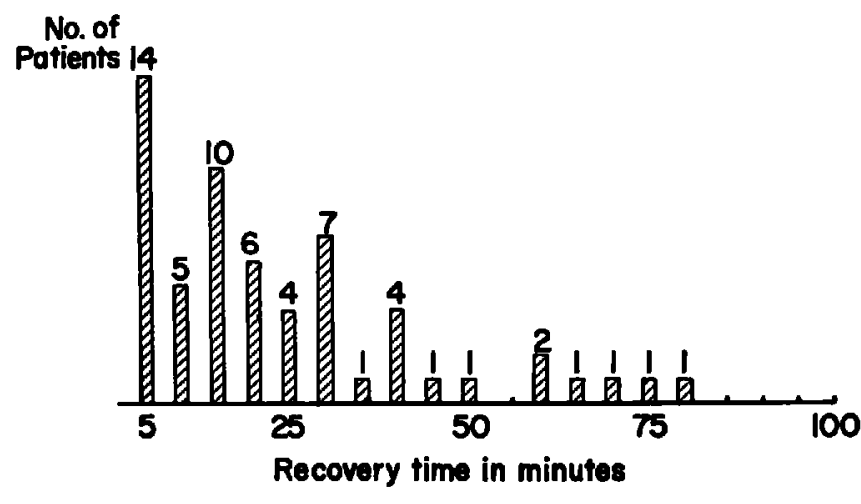

Figure 5

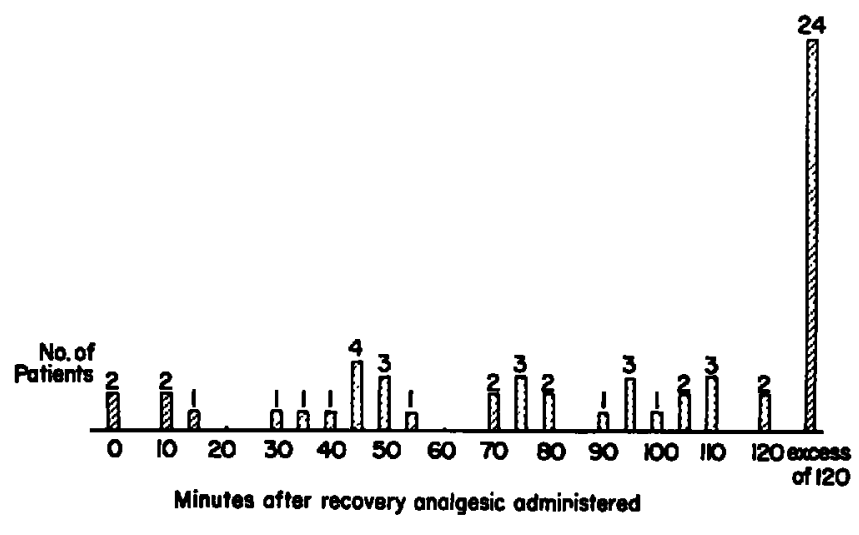

Ficune 6 
if the operative and postoperative period are considered as a continuous process, and the use of these drugs facilitates the use of methoxyflurane. The place of psychopharmacologic agents employed during anaesthesia requires an appraisal of aspects of their action not attempted in this report. However, with suitable controls these drugs can be of value when used individually and in combination, as described herein.

\section{SUMMMARY}

An account is given of the use of droperidol-fentanyl-nitrous-oxide anaesthesia, and observations are made with reference to a similar group of patients anaesthetized with halothane and nitrous oxide. The former technique was found to be excellent, but lacked the technical and pharmacological flexibility necessary for routine use in anaesthesia. The use of droperidol and fentanyl supplemented by minimal quantities of methoxyflurane provided this flexibility, and enabled the operative and postoperative analgesia to be considered as one continuous process.

\section{RéSUMá}

Cent cas d'anesthésie avec protoxide d'azote, oxygène, dropéridol et fentanyl furent étudiés avec un nombre égal de cas anesthésiés au protoxide d'azote et halothane. Avec la première technique il fut constaté qu'il y avait un retour plus rapide de la conscience et consécutif à ce retour de conscience une bonne analgésie et une absence de sensation de fatigue. Des observations sont faites sur l'addition de methoxyflurane et oxygène au fentanyl et dropéridol dans plus de 60 cas. Des constatations préliminaires sur l'état de conscience pendant l'anesthésie démontrent que, en utilisant cette technique, on peut obtenir des réactions au stimulus auditif en l'absence de réactions réflexes respiratoires et cardiovasculaires au stimulus chirurgical.

\section{REFERENCES}

1. WALKKR, REED \& McINTYRE, J. W. R. Clinical Experiences with a Combination of Fentanyl and Droperidol. Canad. Anaesth. Soc. J. 12: 361 (1965).

2. SunUGrter, D. Potentiation of Analgesic Activity of Morphine by Neostigmine. J.A.M.A. 115: 2058 (1940). 